\title{
Correction to: Pretreatment quality of life in patients with rectal cancer is associated with intrusive thoughts and sense of coherence
}

\author{
Dan Asplund $^{1}$ (D) Thue Bisgaard $^{2} \cdot$ David Bock $^{1} \cdot$ Jakob Burcharth $^{3} \cdot$ Elisabeth González $^{1} \cdot$ Eva Haglind $^{1}$. \\ Yanislav Kolev ${ }^{4}$. Peter Matthiessen ${ }^{5}$. Carina Rosander ${ }^{1}$. Jacob Rosenberg ${ }^{3} \cdot$ Kenneth Smedh $^{6}$. \\ Marina Åkerblom Sörensson ${ }^{7} \cdot$ Eva Angenete $^{1}$
}

Published online: 13 January 2018

(C) Springer-Verlag GmbH Germany, part of Springer Nature 2018

Correction to: Int J Colorectal Dis (2017) 32:1639-1647 https://doi.org/10.1007/s00384-017-2900-y

The original version of this article, unfortunately, contained errors.

The errors are listed and are presented correctly as follows:

1. The gender distribution presented in Table 2 Clinical characteristics of the study group (row 3 and 4 ) is incorrect.

Should say:

\begin{tabular}{ccccccc}
\hline & All & \multicolumn{2}{l}{ Curative } & \multicolumn{2}{c}{ Palliative $p$-value } \\
\cline { 3 - 5 } & & All & Not APE & APE & & \\
\hline Sex $(\%)$ & & & & & & $<0.05$ \\
Female & $392(36)$ & $375(35)$ & $283(37)$ & $92(34)$ & $17(23)$ & \\
Male & $693(64)$ & $693(65)$ & $475(63)$ & $180(66)$ & $56(77)$ & \\
\hline
\end{tabular}

The online version of the original article can be found at https://doi.org/10. 1007/s00384-017-2900-y.

Dan Asplund

dan.asplund@vgregion.se

1 Department of Surgery, Institute of Clinical Sciences,

Sahlgrenska Academy, University of Gothenburg,

Scandinavian Surgical, Outcomes Research Group (SSORG),

Sahlgrenska University Hospital/Östra, 41685 Gothenburg, Sweden

2 Department of Surgery, Hvidovre Hospital, University of

Copenhagen, Copenhagen, Denmark
2. The gender distribution presented in Table 3 Comparison between the study group and non-included patients (row 3 and 4) is incorrect.

Should say:

\begin{tabular}{llcc}
\hline & Study group & Non-included & $p$-value \\
\hline Sex $(\%)$ & & & n.s. \\
Female & $392(36)$ & $882(39)$ & \\
Male & $693(64)$ & $1360(61)$ & \\
\hline
\end{tabular}

3 Department of Surgery, Herlev Hospital, University of Copenhagen, Copenhagen, Denmark

4 Department of Surgery, NU Hospital group, Trollhättan, Sweden

5 Department of Surgery, Faculty of Medicine and Health, Örebro University, Örebro, Sweden

6 Department of Surgery, Västmanland's Hospital Västerås, 721 89 Västerås, Sweden

7 Department of Surgery, Central Hospital of Karlstad, Karlstad, Sweden 
The corrected Tables are presented below:

Table 2 Clinical characteristics of the study group

\begin{tabular}{|c|c|c|c|c|c|c|}
\hline & \multirow[t]{2}{*}{ All } & \multicolumn{3}{|l|}{ Curative } & \multirow[t]{2}{*}{ Palliative } & \multirow[t]{2}{*}{$p$-value ${ }^{\mathrm{c}}$} \\
\hline & & All & Not APE & APE & & \\
\hline Number of patients & 1085 & 1012 & 740 & 272 & 73 & \\
\hline $\operatorname{Sex}(\%)$ & & & & & & $<0.05$ \\
\hline Female & $392(36)$ & $375(35)$ & $283(37)$ & $92(34)$ & $17(23)$ & \\
\hline Male & $693(64)$ & $693(65)$ & $475(63)$ & $180(66)$ & $56(77)$ & \\
\hline Age, median (range) & $69(25-100)$ & $69(25-100)$ & $68(25-100)$ & $70(38-91)$ & $70(35-96)$ & $<0.05$ \\
\hline \multicolumn{7}{|l|}{ Tumour stage, cTNM ${ }^{\mathrm{a}}(\%)$} \\
\hline $\mathrm{T} 1-2$ & $269(25)$ & $268(26)$ & $199(27)$ & $69(25)$ & $1(1)$ & $<0.001$ \\
\hline $\mathrm{T} 3$ & $559(51)$ & $525(52)$ & $399(54)$ & $126(46)$ & $34(47)$ & \\
\hline $\mathrm{T} 4$ & $158(15)$ & $128(13)$ & $74(10)$ & $54(20)$ & $30(41)$ & \\
\hline $\mathrm{TX}$ & $99(9)$ & $91(9)$ & $68(9)$ & $23(9)$ & $8(11)$ & \\
\hline No & $426(39)$ & $416(41)$ & $306(41)$ & $110(40)$ & $10(14)$ & $<0.001$ \\
\hline N1-2 & $532(49)$ & $484(48)$ & $352(48)$ & $132(49)$ & $48(66)$ & \\
\hline NX & $127(12)$ & $112(11)$ & $82(11)$ & $30(11)$ & $15(20)$ & \\
\hline M0 & $894(82)$ & 877 (87) & $639(87)$ & $238(87)$ & $17(23)$ & $<0.001$ \\
\hline M1 & $124(12)$ & $77(7)$ & $61(8)$ & $16(6)$ & $47(64)$ & \\
\hline MX & $67(6)$ & $58(6)$ & $40(5)$ & $18(7)$ & $9(12)$ & \\
\hline Tumour height ${ }^{\mathrm{b}}$, median (range) & $8(0-15 ;$ IQR 6$)$ & $8(0-15 ;$ IQR 6$)$ & $10(0-15 ;$ IQR 4$)$ & $4(0-15 ;$ IQR 3$)$ & $9(2-15 ;$ IQR 7$)$ & n.s. \\
\hline
\end{tabular}

n.s. $=p$-value $<0.05$

${ }^{\text {a }}$ Clinical TNM-stage, based on radiology

${ }^{\mathrm{b}}$ Measured in centimetres from the anal verge on retraction of a rigid rectoscope in the left lateral position. Data missing in 64 patients

${ }^{\mathrm{c}}$ Curative versus palliative patients 
Table 3 Comparison between the study group and non-included patients

\begin{tabular}{|c|c|c|c|}
\hline & Study group & Non-included $^{\mathrm{a}}$ & $p$-value \\
\hline Number of patients & 1085 & 2242 & \\
\hline $\operatorname{Sex}(\%)$ & & & n.s. \\
\hline Female & $392(36)$ & $882(39)$ & \\
\hline Male & $693(64)$ & $1360(61)$ & \\
\hline Age, median (range) & $69(25-100)$ & $70(23-100)$ & $<0.001$ \\
\hline ASA grade ${ }^{\mathrm{b}}(\%)$ & & & $<0.001$ \\
\hline 1 & $230(24.5)$ & $394(22)$ & \\
\hline 2 & $560(60)$ & $982(54)$ & \\
\hline 3 & $142(15)$ & $404(22)$ & \\
\hline 4 & $5(0.5)$ & $28(2)$ & \\
\hline \multicolumn{4}{|l|}{ Tumour stage, $\mathrm{cTNM}^{\mathrm{c}}(\%)$} \\
\hline $\mathrm{T} 1-2$ & $269(25)$ & $484(22)$ & $<0.001$ \\
\hline $\mathrm{T} 3$ & $559(51)$ & $936(42)$ & \\
\hline $\mathrm{T} 4$ & $158(15)$ & $475(21)$ & \\
\hline $\mathrm{TX}$ & $99(9)$ & $347(15)$ & \\
\hline No & $426(39)$ & 420 (19) & $<0.001$ \\
\hline $\mathrm{N} 1-2$ & $532(49)$ & $742(33)$ & \\
\hline NX & $127(12)$ & $1080(48)$ & \\
\hline M0 & $894(82)$ & $1749(78)$ & $<0.001$ \\
\hline M1 & $124(12)$ & $408(18)$ & \\
\hline MX & $67(6)$ & $85(4)$ & \\
\hline Tumour height ${ }^{\mathrm{d}}$, median (range) & 8 (0-15; IQR 6) & $8(0-15 ;$ IQR 6$)$ & n.s. \\
\hline
\end{tabular}

n.s. $=p$-value $<0.05$

${ }^{\text {a }}$ Patients treated at participating hospitals during the inclusion period but not included in the study

${ }^{\mathrm{b}}$ ASA (American Society of Anesthesiologists) grade is missing in patients scheduled for palliative treatment

${ }^{\mathrm{c}}$ Clinical TNM-stage, based on radiology

${ }^{d}$ Measured in centimetres from the anal verge on retraction of a rigid rectoscope in the left lateral position. Data is missing in 64 patients in the study group and in 55 non-included patients

\section{Discussion, p. 9.}

Says: "Women were overrepresented among included compared to non-included patients, but the sex distribution in the study group was comparable to that reported for all new cases of colorectal cancer in Europe 2012 [39].”

Should say: "The sex distribution was comparable to what is reported in the registry." 